\title{
Patient characteristics associated with screening positive for Alzheimer's disease and related dementia
}

This article was published in the following Dove Press journal:

Clinical Interventions in Aging

\author{
Nicole R Fowler ${ }^{1-4}$ \\ Anthony J Perkins ${ }^{4}$ \\ Sujuan $\mathrm{Gao}^{5}$ \\ Greg A Sachs ${ }^{1-3}$ \\ Austin K Uebelhor ${ }^{2,3}$ \\ Malaz A Boustani ${ }^{1-4}$ \\ 'Department of Medicine, Indiana \\ University School of Medicine, \\ Indianapolis, IN, USA; ${ }^{2}$ Indiana \\ University Center for Aging Research, \\ Indianapolis, IN, USA; ${ }^{3}$ Regenstrief \\ Institute, Inc., Indianapolis, IN, USA; \\ ${ }^{4}$ Center for Health Innovation and \\ Implementation Science, Indiana \\ Clinical and Translational Science \\ Institute, Indianapolis, IN, USA; \\ ${ }^{5}$ Department of Biostatistics, Indiana \\ University School of Medicine, \\ Indianapolis, IN, USA
}

Introduction: Screening all older adults for Alzheimer's disease and related dementias (ADRD) in primary care may not be acceptable or feasible. The goal of this study was to identify factors that could optimize screening in primary care and enhance its feasibility.

Methods: This is a cross-sectional study in rural, suburban, and urban primary care practices in Indiana. A total of 1,723 patients $\geq 65$ years of age were screened for ADRD using the Memory Impairment Screen. Logistic regression was used to identify patient-specific factors associated with screening positive for ADRD.

Results: The positive screening rate was $4.9 \%$. Rates varied significantly across the three study sites. The rural site had the lowest rate $(2.8 \%)$, which was significantly lower than the rates at the suburban $(5.6 \%)$ and urban $(6.6 \%)$ sites $(P<0.01)$. Patient age, sex, and education were significantly $(P<0.05)$ associated with screening positive for ADRD.

Conclusion: Targeted screening of patients at risk for ADRD may represent a more optimal and feasible screening alternative to population screening.

Keywords: dementia screening, Alzheimer's disease screening, primary care

\section{Background}

The National Academy of Sciences, the National Plan to Address Alzheimer's Disease, and the Affordable Care Act, through the Medicare Annual Wellness Visit, all identify early detection of Alzheimer's disease and related dementias (ADRD) as a core aim for improving the care quality for older adults. ${ }^{1-3}$ ADRD are debilitating conditions that impair memory, thought processes, and functioning, primarily among older adults. ${ }^{4}$ Nevertheless, the USA Preventive Services Task Force currently does not recommend ADRD screening due to the lack of evidence about the risks and benefits of early detection as well as lack of effective treatments. ${ }^{5}$

Given the uncertainty regarding routine, population screening, targeted screening of people at risk for ADRD may represent an alternative to traditional population screening. ${ }^{6,7}$ Patient characteristics, such as education and comorbidity burden, ${ }^{8,9}$ as well as lifestyle factors, ${ }^{10}$ have been shown to correlate with cognitive impairment screening results. For example, some research has shown that patients who score worse on cognitive assessment are more likely to be female, African-American, and have less years of formal education. ${ }^{1-13}$ However, sample sizes of previous studies have been relatively small with limited generalizability.

The aim of this study is to report the rate of positive ADRD screening tests in a large and diverse cohort of older adults from urban, suburban, and rural sites and to
Correspondence: Nicole R Fowler Indiana University School of Medicine, II 0 I West IOth, Indianapolis, IN 46202, USA

$\mathrm{Tel}+13172749021$

Fax +I 3172749307

Email fowlern@iupui.edu (c)
hereby accept the Terms. Non-commercial uses of the work are permitted without any furcher permission from Dove Medical Press Limited, provided the work is properly attributed. For permission for commercial use of this work, please see paragraphs 4.2 and 5 of our Terms (https://www.dovepress.com/terms.php). 
identify factors associated with screening positive. Results from this study are intended to help determine the optimal setting or population for targeted ADRD screening efforts.

\section{Methods}

\section{Participants}

Participants for this study were enrolled in the Indiana University Cognitive Health Outcomes Investigation of the Comparative Effectiveness of Dementia Screening (CHOICE) trial. CHOICE is an ongoing, multisite randomized controlled trial to test the risks and benefits of screening for ADRD in primary care. ${ }^{14}$ It includes 4,005 primary care patients aged 65 years or older who receive their primary care from one of the three health care systems in central Indiana. The cohort of patients for these analyses includes 1,723 individuals who are enrolled in the CHOICE trial and were randomized to be screened for ADRD. The sites include Eskenazi Health, Indiana University Health (IUH) Indianapolis and IUH Arnett. Eskenazi Health is an urban, safety net health care system with eleven federally qualified health care centers staffed by faculty and residents of Indiana University School of Medicine. IUH Indianapolis includes five suburban primary care practices in Marion County, IN. The third site, IUH Arnett, is a regional health care center in rural Indiana, which is part of the IUH system and serves patients in the cities of Lafayette and West Lafayette, and the surrounding areas in Tippecanoe County, IN. Patients from eight primary care practices in the Arnett catchment area were recruited for the CHOICE trial. The CHOICE trial was approved by the institutional review boards (IRBs) of Indiana University-Purdue University in Indianapolis and IUH Arnett Hospital and is registered with ClinicalTrials.gov (NCT01699503). Participants who were enrolled in-person provided written informed consent to participate in the study. Participants who were enrolled by telephone provided a verbal consent, as per our waiver of written informed consent from the IRBs at Indiana University-Purdue University in Indianapolis and IUH Arnett Hospital.

Patients were eligible if they were 65 years or older, had at least one visit to their primary care physician in the past 12 months, did not already have a previous or preexisting diagnosis of ADRD or mild cognitive impairment, and had the ability to communicate in English. Patients were excluded from the study if they were a permanent resident of a nursing facility, had a serious mental illness, or had been given a prescription for a cholinesterase inhibitor or memantine. Patients were randomized equally into two arms (screening or no screening). ${ }^{14}$
Patients randomized to the screening arm were screened with the Memory Impairment Screen (MIS) at baseline either in-person or by phone. ${ }^{15,16}$ The MIS required 4 minutes to administer and included a non-cued and cued recall. Participants were presented with four target words and associated cues. After 2-3 minutes of unrelated tasks, participants were asked to recall the four words. For words not identified by free recall, the interviewer provided the cues for those words. Scoring the MIS consisted of multiplying the number of free recall items by two and adding the number of cued recall items, resulting in a possible score range of 0-8. Using a cutoff score of 4 or less, the MIS has been shown to have $86 \%$ sensitivity and $97 \%$ specificity for identifying memory impairment. ${ }^{15}$ The telephone version of the MIS, the MIS-T, displayed similar characteristics with a sensitivity of $78 \%$ and a specificity of $93 \% .{ }^{16}$ All patients who scored a 4 or less on the MIS were referred for a voluntary diagnostic assessment. Results comparing the positive screening tests with diagnostic assessment data will be presented in an upcoming paper. Patient demographic variables were assessed during the baseline interview. The presence of nine common geriatric chronic conditions and the Charlson Comorbidity Index score ${ }^{17}$ were obtained from the Indiana Network for Patient Care (INPC), which is a regional health information infrastructure that includes a network of over 80 hospitals and their patient medical record systems. The INPC research database contains over 17.2 million individual patients, 4.6 billion clinical observations, and 165 million text reports, with $68 \%$ of the Indiana population captured in $2014 .{ }^{18}$

\section{Statistical analyses}

We used Fisher's exact test to compare categorical demographic variables across the three different study sites. We used Kruskal-Wallis test for differences in the Charlson Comorbidity Index score, which has a skewed distribution. We used Fisher's exact test to compare differences in the percentage of patients screening positive by sociodemographic and comorbidity factors. When items with more than two categories were found to be significant, we performed pairwise comparisons to determine group differences. We used the step-down Bonferroni method to adjust for multiple pairwise comparisons within each variable. We used a logistic regression model to simultaneously examine the association of demographic factors and study site with positive ADRD screening tests. All analyses were conducted using SAS v9.4 (Cary, NC, USA). 


\section{Results}

\section{Patient demographic and clinical characteristics by study site}

In the CHOICE trial, 4,005 patients were enrolled, and 2,008 were randomized to the screening group. To ensure complete and accurate data, 1,723 were included in the analysis. To meet the enrollment targets, 7,317 patients were approached, and the exclusion and refusal rate for the study was $43 \%$.

Demographic and comorbidity comparisons by study site are presented in Table 1. There are significant differences in sociodemographics across the three sites. Patients at the urban site (Eskenazi Health) were significantly younger and had fewer years of education than patients at the suburban and rural sites (IUH Indianapolis and IUH Arnett, respectively; both $P<0.001)$. Race also differed significantly, with almost no African-American patients at the rural site $(P<0.001)$. Specifically, $27 \%$ of patients at suburban site were African-American, while the majority of patients (60\%) at the urban site were African-American. Although sex differed by site, the majority of patients were female at all three sites $(63 \%-72 \%)$. Patients at the rural site had significantly fewer chronic comorbidities $(P<0.001)$, which resulted in significantly lower Charlson Comorbidity Index scores as compared to patients at suburban and urban sites (2.0 versus 3.4 and 3.8, respectively; $P<0.001$; Table 1). Pairwise comparisons for race, age, education, sex, and comorbidity, by site, did not differ from the overall comparisons presented in Table 1 (results not shown).

\section{Positive screening rate by study site and patient sociodemographics}

Positive screening rates by sociodemographic characteristics and comorbid conditions are presented in Table 2. Overall, the positive screening rate was $4.9 \%$; however, the rates varied significantly $(P=0.003)$ across the three study sites. The rural site had the lowest rate of patients who screened positive $(2.8 \%)$, which was significantly lower than the rates at the suburban and urban sites $(5.6 \%[P=0.007]$ and $6.6 \%$ $[P=0.004]$, respectively). Patients aged 80 years and older as well were significantly more likely to screen positive than patients aged $65-69$ years $(P=0.027)$ and patients aged

Table I Demographic and clinical characteristics by site

\begin{tabular}{|c|c|c|c|c|}
\hline Variable & $\begin{array}{l}\text { Urban site }^{a} \\
(\mathbf{N}=725)\end{array}$ & $\begin{array}{l}\text { Suburban site } \\
(\mathrm{N}=345)\end{array}$ & $\begin{array}{l}\text { Rural site } \\
(\mathrm{N}=653)\end{array}$ & $P$-value \\
\hline Age in years, \% (n) & & & & $<0.001$ \\
\hline $65-69$ & $51.3(372)$ & $26.4(91)$ & $18.2(119)$ & \\
\hline $70-79$ & $39.3(285)$ & $49.0(169)$ & $53.3(348)$ & \\
\hline$\geq 80$ & $9.4(68)$ & $24.6(85)$ & $28.5(186)$ & \\
\hline Sex, \% (n) & & & & 0.002 \\
\hline Male & $27.9(202)$ & $37.4(129)$ & $34.6(225)$ & \\
\hline Female & $72.1(523)$ & $62.6(216)$ & $65.4(428)$ & \\
\hline Race, \% (n) & & & & $<0.001$ \\
\hline African-American & $59.8(432)$ & $27.0(93)$ & $0.2(\mathrm{I})$ & \\
\hline White & $38.0(275)$ & $71.3(246)$ & $98.5(643)$ & \\
\hline Other & $2.2(16)$ & $1.7(6)$ & $\mathrm{I} .4(9)$ & \\
\hline Education, \% (n) & & & & $<0.001$ \\
\hline $0-8$ years & $10.5(75)$ & $0.6(2)$ & $0.6(4)$ & \\
\hline $9-11$ years & $31.5(226)$ & $5.2(18)$ & $5.8(38)$ & \\
\hline High school or high school equivalent & $29.7(213)$ & $32.6(112)$ & $37.7(246)$ & \\
\hline Some college, college degree, or postgraduation & $28.3(203)$ & $61.5(211)$ & $55.5(364)$ & \\
\hline \multicolumn{5}{|l|}{ Comorbidities, \% (n) } \\
\hline Hypertension & $91.6(662)$ & $89.6(309)$ & $75.5(493)$ & $<0.001$ \\
\hline Diabetes & $52.8(382)$ & $48.1(166)$ & $30.2(197)$ & $<0.001$ \\
\hline Myocardial infarction & I5.I (109) & $13.6(47)$ & $8.6(56)$ & 0.001 \\
\hline Congestive heart failure & $24.2(175)$ & $20.3(70)$ & $9.5(62)$ & $<0.001$ \\
\hline COPD & $55.5(40 \mathrm{I})$ & 46.1 (159) & $22.5(147)$ & $<0.001$ \\
\hline Liver disease & $6.9(50)$ & $9.6(33)$ & $4.0(26)$ & 0.002 \\
\hline History of cancer & $14.5(105)$ & $23.5(8 I)$ & $10.6(69)$ & $<0.001$ \\
\hline Depression & $38.4(278)$ & $31.3(108)$ & $17.0(|I|)$ & $<0.001$ \\
\hline Charlson Comorbidity Index score, mean (SD) & $3.4(3.0)$ & $3.8(3.3)$ & $1.9(2.3)$ & $<0.001$ \\
\hline
\end{tabular}

Notes: aEskenazi Health. 'Indiana University Health, Indianapolis. Indiana University Health, Arnett. 
Table 2 Positive screening rate by site and demographics

\begin{tabular}{|c|c|c|}
\hline Variable & $\begin{array}{l}\text { Patients who } \\
\text { screened } \\
\text { positive }\end{array}$ & $P$-value \\
\hline $\begin{array}{l}\text { Overall rate of positive ADRD } \\
\text { screening tests, } \%(n)\end{array}$ & $4.9(83)$ & \\
\hline Study site, \% (n) & & 0.003 \\
\hline$U_{r b a n}{ }^{a}$ & $6.6(46)$ & \\
\hline Suburban ${ }^{b}$ & $5.6(19)$ & \\
\hline Rural $^{\mathrm{c}}$ & $2.8(18)$ & \\
\hline Age in years, \% (n) & & 0.015 \\
\hline $65-69$ & $4.0(23)$ & \\
\hline $70-79$ & $4.2(33)$ & \\
\hline$\geq 80$ & $8.2(27)$ & \\
\hline Sex, \% (n) & & 0.092 \\
\hline Male & $6.2(34)$ & \\
\hline Female & $4.3(49)$ & \\
\hline Race, \% (n) & & 0.002 \\
\hline African-American & $7.9(40)$ & \\
\hline White & $3.6(42)$ & \\
\hline Other & $3.3(1)$ & \\
\hline Education, \% (n) & & $<0.001$ \\
\hline $0-8$ years & $10.3(8)$ & \\
\hline $9-11$ years & $8.4(23)$ & \\
\hline High school or high school equivalent & $5.5(31)$ & \\
\hline $\begin{array}{l}\text { Some college, college degree, or } \\
\text { postgraduation }\end{array}$ & $2.7(2 \mathrm{I})$ & \\
\hline \multicolumn{3}{|l|}{ Comorbidities, \% (n) } \\
\hline Hypertension & $5.1(73)$ & 0.530 \\
\hline Diabetes & $5.7(4 I)$ & 0.256 \\
\hline Myocardial infarction & $6.7(14)$ & 0.228 \\
\hline Congestive heart failure & $7.0(21)$ & 0.076 \\
\hline COPD & $6.5(45)$ & 0.016 \\
\hline Liver disease & $5.6(6)$ & 0.646 \\
\hline History of cancer & $5.6(14)$ & 0.527 \\
\hline Depression & $5.0(24)$ & 1.000 \\
\hline
\end{tabular}

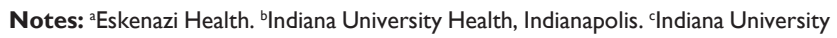
Health, Arnett.

Abbreviation: ADRD, Alzheimer's disease and related dementias.

70-79 years $(P=0.027)$. African-American patients were significantly more likely to screen positive for memory impairment than white patients $(P=0.002)$. There were significant differences $(P<0.001)$ in the rate of positive screening by education level. Specifically, those patients who had some college, a college degree, or postgraduate education had significantly lower rates than those with $0-8$ years of education ( $P=0.016)$ and those with $9-11$ years of education $(P=0.001)$. Patients with a history of COPD were also significantly more likely to screen positive compared to patients without COPD $(P=0.016$; Table 2).

\section{Logistic regression analysis to identify factors associated with positive screening}

Logistic regression analysis was conducted to identify factors associated with odds of screening positive for memory impairment (Table 3). Younger age was associated with reduced odds of screening positive (65-69 years: OR 0.32, 95\% CI $0.17,0.60 ; 70-79$ years: OR $0.40,95 \%$ CI 0.23 , 0.69 ; both $P<0.001)$. However, males and those with less education had increased odds of screening positive (both $P<0.05$ ). Odds of a positive screening test increased incrementally with decreasing years of education such that those with $0-8$ years of education had an OR of 3.16 compared to those with at least a high school degree or more years of education (OR 2.05; Table 3).

\section{Discussion}

This study aimed at exploring the rate of positive screening tests for memory impairment in a large and diverse cohort of older primary care patients from urban, suburban, and rural sites and at identifying factors associated with screening positive for ADRD in primary care. The rates of positive screening were greater in patients aged $\geq 80$ years, males, African-Americans, and those with less education.

Our study found a wide variation in positive screening rates, ranging from $2.8 \%$ to $6.6 \%$, across the three sites, with an overall positive screening rate of $4.9 \%$. Our overall rate was lower than other ADRD screening studies conducted in primary care. ${ }^{19-22}$ When explored by site, the urban site had the highest rate of positive screening at $6.6 \%$, which was lower than the rate reported in a previous screening study conducted at the same urban site for this analysis 5 years earlier, which was $13 \% .{ }^{12}$ The lower rates could be reflective of our choice of screening instrument, changing incidence rates, ${ }^{23}$ or our population which was generally younger with more years of formal education, the last two being associated with decreased likelihood of ADRD. ${ }^{8,24,25}$ Alternatively, the unexpectedly low positive screening rate could be a reflection of incidence rates, compared to prevalence rates, given the number of ADRD-related studies our group has conducted in these settings over the past two decades., ${ }^{8,12,19,26-28}$ Moreover, recent epidemiological studies have shown a reduction in the incidence rates of dementia, ${ }^{23,29,30}$ and an analysis of the Framingham study has shown a greater decline in younger age groups. ${ }^{31}$ Changing patient factors, including increased education and lifetime cognitive stimulation, ${ }^{32}$ decreased vascular risk factors,,${ }^{33}$ or tobacco control,${ }^{34}$ may contribute to the decline. Also, others have suggested that the decline is greater in different age groups, especially in younger age groups. Additionally, the screening instrument used in this study or the lack of adjustment of the cutoff score by age, sex, and education may have contributed to the low rates. Other tools created for and tested in primary care that 
Table 3 Regression results for screening positive for ADRD

\begin{tabular}{|c|c|c|c|c|}
\hline \multirow[t]{2}{*}{ Variable } & \multicolumn{2}{|c|}{ Univariate results } & \multicolumn{2}{|c|}{ Multivariate results } \\
\hline & OR (95\% CI) & $P$-value & OR (95\% Cl) & $P$-value \\
\hline Study site & & 0.006 & & 0.259 \\
\hline Rural $^{\mathrm{a}}$ & $0.40(0.23,0.70)$ & 0.001 & $0.62(0.29,1.36)$ & 0.234 \\
\hline Suburban ${ }^{\mathrm{b}}$ & $0.84(0.48,1.46)$ & 0.536 & $1.12(0.58,2.19)$ & 0.735 \\
\hline Urban (reference) ${ }^{c}$ & 1.00 & & 1.00 & \\
\hline Age in years & & 0.012 & & 0.001 \\
\hline $65-69$ & $0.48(0.27,0.84)$ & 0.011 & $0.32(0.17,0.60)$ & $<0.001$ \\
\hline $70-79$ & $0.50(0.29,0.84)$ & 0.009 & $0.40(0.23,0.69)$ & 0.001 \\
\hline$\geq 80$ (reference) & 1.00 & & 1.00 & \\
\hline \multicolumn{5}{|l|}{ Sex } \\
\hline Female & $0.68(0.43,1.06)$ & 0.087 & $0.57(0.36,0.91)$ & 0.019 \\
\hline Race & & 0.001 & & 0.126 \\
\hline African-American & $2.28(\mathrm{I} .46,3.57)$ & $<0.001$ & $1.80(0.90,3.60)$ & 0.128 \\
\hline Other & $0.91(0.12,6.84)$ & 0.927 & $1.10(0.14,8.54)$ & 0.924 \\
\hline White (reference) & 1.00 & & 1.00 & \\
\hline Education & & $<0.001$ & & 0.022 \\
\hline $0-8$ years & $4.07(1.74,9.52)$ & 0.001 & $3.16(1.25,8.02)$ & 0.016 \\
\hline $9-11$ years & $3.26(1.77,5.99)$ & $<0.001$ & $2.48(1.26,4.90)$ & 0.009 \\
\hline High school or high school equivalent & $2.08(1.18,3.65)$ & 0.011 & $2.05(1.15,3.65)$ & 0.015 \\
\hline Some college, college degree, or postgraduation (reference) & 1.00 & & 1.00 & \\
\hline \multicolumn{5}{|l|}{ Comorbidities } \\
\hline COPD & $1.76(1.13,2.74)$ & 0.013 & $1.43(0.89,2.28)$ & 0.139 \\
\hline
\end{tabular}

Notes: andiana University Health, Arnett. 'Indiana University Health, Indianapolis. 'Eskenazi Health.

Abbreviation: ADRD, Alzheimer's disease and related dementias.

are more sensitive to factors such as education or age, for example, the Mini-Cog and the General Practitioner assessment of Cognition, have been found to be viable ADRD screening tools that are recommended for use in primary care settings. ${ }^{3,22,35-41}$ We selected the MIS because of its psychometric properties, feasibility of use in the primary care setting, and its administration over telephone. Future studies of population-level ADRD screening may want to consider using other instruments, such as the Montreal Cognitive Assessment, which has recently been validated in a national sample. ${ }^{24}$

Of the three sites, the rural site had the lowest positive screening rate, despite the fact that a higher proportion of participants was $\geq 80$ years of age. However, this site was screened primarily by phone, and its population was also highly educated (93.2\% had at least a high school education) and had less medical comorbidities, both of which are known to be related to the risk of ADRD. ${ }^{25-27,33,34}$ Moreover, this group had a higher socioeconomic status (data not shown), which can positively contribute to reduced comorbidities. ${ }^{35}$

We found that older age and decreasing years of education were significantly associated with increased likelihood of a positive screening, which is consistent with the current literature. ${ }^{24-27,42}$ However, we found that males were more likely to screen positive than females, which has been inconsistent with the current literature of screening in primary care. $^{43-45}$

When implementing a screening program in primary care, the goal is to maximize benefits and minimize harms of detection. For ADRD screening, minimizing the harms may be best achieved by using an instrument with high specificity to minimize false-positive screening as well as targeted screening., 36 To optimize the yield of ADRD screening, future programs may target primary care patients who are older, have less education, and suffer from comorbidities.

\section{Limitations}

There are some limitations to the study. First, the refusal rate for the study was high (43\%). Patients who refused to participate in the study may be at higher risk for ADRD; therefore, our overall rate of $4.9 \%$ of patients who screened positive may be an underestimate of the true rate in our population. Also, patients assessed by phone were from the rural study site (IUH Arnett); therefore, we cannot determine if the differences were due to the mode of administration of the screening test or the demographic differences observed in that population. Another limitation is that we did not use age- or education-specific cutoff points for the MIS or MIS-T, and the findings for site differences could be due to age, sex, and education differences among the sites. 


\section{Conclusion}

The low rates of positive screening and the regional variation observed in this study suggest that more targeted programs to identify patients at risk for ADRD may represent a better alternative to population screening. Such targeted screening strategies could use patient characteristics, including those identified in the present study (ie, older age, less education, and non-white), to identify the best screening tool and to select potential patients who may benefit most from screening. These strategies will likely minimize any harm associated with screening as well as maximize the benefit of detecting early cases.

\section{Acknowledgment}

This study was supported by grant R01 AG052508 from the National Institute on Aging.

\section{Disclosure}

The authors report no conflicts of interest in this work.

\section{References}

1. Institute of Medicine. Crossing the Quality Chasm: A New Health System for the 21st Century. Washington, DC: National Academies Press; 2001.

2. Office of the Assistant Secretary for Planning and Evaluation [webpage on the Internet]. National Plan to Address Alzheimer's Disease. Available from: https://aspe.hhs.gov/report/national-plan-addressalzheimers-disease-2016-update. Accessed July 14, 2017.

3. Cordell CB, Borson S, Boustani M, et al. Medicare detection of cognitive impairment workgroup, Alzheimer's Association recommendations for operationalizing the detection of cognitive impairment during the Medicare Annual Wellness Visit in a primary care setting. Alzheimers Dement. 2013;9:141-150.

4. US Department of Health and Human Services. Office of the Assistant Secretary for Planning and Evaluation [webpage on the Internet]. The National Alzheimer's Planning Act. Available from: https://aspe.hhs.gov/whatalzheimers-disease-and-related-dementias. Accessed April 27, 2018.

5. Moyer VA; U.S. Preventive Services Task Force. Screening for cognitive impairment in older adults: U.S. Preventive Services Task Force recommendation statement. Ann Intern Med. 2014;160:791-797.

6. Kallumpuram S, Sudhir Kumar CT, Khan B, Gavins V, Khan A, Iliffe S. Targeted case finding for dementia in primary care: Surrey Downs dementia diagnosis project. BMJ Qual Improv Rep. 2015;4(1).

7. van den Dungen P, Moll van Charante EP, van arwijk HW, van der Horst HE, van de Ven PM, van Hout HP. Case-finding of dementia in general practice and effects of subsequent collaborative care; design of a cluster RCT. BMC Public Health. 2012;12:609.

8. Callahan CM, Hall KS, Hui SL, Musick BS, Unverzagt FW, Hendrie HC. Relationship of age, education, and occupation with dementia among a community-based sample of African Americans. Arch Neurol. 1996; 53:134-140.

9. Beydoun MA, Beydoun HA, Gamaldo AA, Teel A, Zonderman AB, Wang Y. Epidemiologic studies of modifiable factors associated with cognition and dementia: systematic review and meta-analysis. $B M C$ Public Health. 2014;14:463.

10. Livingston G, Sommerlad A, Orgeta V, et al. Dementia prevention, intervention, and care. Lancet. 2017;390(10113):2673-2734.

11. Mehta KM, Simonsick EM, Rooks R, et al. Black and white differences in cognitive function test scores: what explains the differences? $\mathrm{J} \mathrm{Am}$ Geriatr Soc. 2004;52(12):2120-2127.
12. Fowler NR, Frame A, Perkins AJ, et al. Traits of patients who screen positive for dementia and refuse diagnostic assessment. Alzheimers Dement (Amst). 2015;1:236-241.

13. Hall CB, Derby C, LeValley A, Katz MJ, Verghese J, Lipton RB. Education delays accelerated decline on a memory test in persons who develop dementia. Neurology. 2007;69:1657-1664.

14. Fowler NR, Harrawood A, Frame A, et al. The Indiana University Cognitive Health Outcomes Investigation of the Comparative Effectiveness of dementia screening (CHOICE) study: study protocol for a randomized controlled trial. Trials. 2014;15:209.

15. Kuslansky G, Buschke H, Katz MJ, Sliwinski M, Lipton RB. Screening for Alzheimer's disease: the memory impairment screen versus the conventional three-word memory test. J Am Geriatr Soc. 2002;50: 1086-1091.

16. Lipton RB, Katz MJ, Kuslansky G, et al. Screening for dementia by telephone using the memory impairment screen. J Am Geriatr Soc. 2003; 51:1382-1390.

17. Charlson ME, Pompei P, Ales KL, MacKenzie CR. A new method of classifying prognostic comorbidity in longitudinal studies: development and validation. J Chron Dis. 1987;40:373-383.

18. McDonald CJ, Overhage JM, Barnes M, et al; INPC Management. The Indiana Network for Patient Care: a working local health informant infrastructure. Health Affairs (Millwood). 2005;24(5):1214-1220.

19. Boustani M, Callahan CM, Unverzagt FW, et al. Implementing a screening and diagnosis program for dementia in primary care. $J$ Gen Intern Med. 2005;20:572-577.

20. Wu YT, Beiser AS, Breteler MMB, et al. The changing prevalence and incidence of dementia over time - current evidence. Nat Rev Neurol. 2017; 13:327-339.

21. Boise L, Eckstrom E, Fagnan L, et al. The Rural Older Adult Memory (ROAM) Study: a practice-based intervention to improve dementia screening and diagnosis. J Am Board Fam Med. 2010;23(4):486-498.

22. Borson S, Scanlan J, Hummel J, Gibbs K, Lessig M, Zuhr E. Implementing routine cognitive screening of older adults in primary care: process and impact on physicians behavior. J Gen Int Med. 2007;22(6): $811-817$.

23. Langa KM, Larson EB, Crimmins EM, et al. A comparison of the prevalence of dementia in the United States in 2000 and 2012. JAMA Intern Med. 2017;177:51-58.

24. Dale W, Kotwal AA, Shega JW, et al. Cognitive function and its risk factors among older US adults living at home. Alzheimer Dis Assoc Disord. Epub 2018 Jan 12.

25. Mortel KF, Meyers JS, Herod B, Thornby J. Education and occupation as risk factors for dementias of the Alzheimer and ischemic vascular types. Dement Geriatr Cogn Dis. 1995;6:55-62.

26. White L, Katzman R, Losonczy K, et al. Association of education with incidence of cognitive impairment in three established population for epidemiologic studies of the elderly. J Clin Epidemiol. 1994; 47(4):363-374

27. Callahan CM, Hendrie HC, Tierney WM. Documentation and evaluation of cognitive impairment in elderly primary care patients. Ann Intern Med. 1995; 122:422-429.

28. Fowler NR, Boustani MA, Frame A, et al. Impact of patients' perceptions on dementia screening in primary care. J Am Geriatr Soc. 2012;60(6): 1037-1043.

29. Fowler NR, Perkins AJ, Turchan HA, et al. Older primary care patients' attitudes and willingness to screen for dementia. J Aging Res. 2015;2015:423265.

30. Matthews FE, Stephan BC, Robinson L, et al. Cognitive Function and Ageing Studies (CFAS) Collaboration: a two decade dementia incidence comparison from the Cognitive Function and Ageing Studies I and II. Nat Commun. 2016;7:11398.

31. Prince M, Ali GC, Guerchet M, Prina AM, Albanese E, Wu YT. Recent global trends in the prevalence and incidence of dementia, and survival with dementia. Alzheimers Res Ther. 2016;8:23.

32. Satizabal CL, Beiser A, Chêne G, et al. Temporal trends in dementia incidence in the Framingham Study [abstract 05-03-05]. Alzheimers Dement. 2014;10:296. 
33. Ott A, Breteler MM, van Harskamp F, et al. Prevalence of Alzheimer's disease and vascular dementia: association with education. The Rotterdam study. BMJ. 1995;310:970-973.

34. Pimenta FA, Bicalho MA, Romano-Silva MA, Moraes EN, Rezende NA. Chronic diseases, cognition, functional decline, and the Charlson index in elderly people with dementia. Rev Assoc Med Bras. 2013;59: 326-334.

35. Schrijvers CT, Coebergh JW, Mackenbach JP. Socioeconomic status and comorbidity among newly diagnosed cancer patients. Cancer. 1997;80:1482-1488.

36. Borson S, Scanlon JM, Chen PJ, et al. The Mini-Cog as a screen for dementia: validation in a population-based sample. J Am Geriatr Soc. 2003;51:1451-1454.

37. Brodaty H, Pond D, Kemp NM, et al. The GPCOG: a new screening test for dementia designed for general practice. J Am Geriatr Soc. 2002; 50(3):530-534.

38. Bradford A, Kunik ME, Schulz P, Williams SP, Singh H. Missed and delayed diagnosis of dementia in primary care: prevalence and contributing factors. Alzheimer Dis Assoc Disord. 2009;23:306-314.

39. Lorentz WJ, Scanlan JM, Borson S. Brief screening tests for dementia. Can J Psychiatry. 2002;47:723-733.

40. Brodaty H, Low LF, Gibson L, Burns K. What is the best dementia screening instrument for general practitioners to use? Am J Geriatr Psychiatry. 2006;14:391-400.
41. Milne A, Culverwell A, Guss R, Tuppen J, Whelton R. Screening for dementia in primary care: a review of the use, efficacy, and quality of measures. Int Psychogeriatr. 2008;20:911-926.

42. Sharp ES, Gatz M. The relationship between education and dementia: an updated systematic review. Alzheimer Dis Assoc Disord. 2011;25(4): 289-304.

43. Hebert LE, Weuve J, Scherr PA, Evans DA. Alzheimer disease in the United States (2010-2050) estimated using the 2010 census. Neurology. 2013;80(19):1778-1783.

44. Lin KA, Choudhury KR, Rathakrishnan BG, Marks DM, Petrella JR, Doraiswamy PM. Marked gender differences in progression of mild cognitive impairment over 8 years. Alzheimers Dement (N Y). 2015;1(2): 103-110.

45. Borland E, Nagga K, Nilsson PM, Minthin L, Nilsson ED, Palmgvist SJ. The Montreal Cognitive Assessment: normative data from a large Swedish population-based cohort. J Alzheimers Dis. 2017;59(3): 893-901.

46. Moise P, Schwarzinger M, Um MY; Dementia Experts' Group. Dementia care in 9 OECD countries: a comparative analysis. Report No. 13. Paris: Organisation for Economic Cooperation and Development; 2004.
Clinical Interventions in Aging

\section{Publish your work in this journal}

Clinical Interventions in Aging is an international, peer-reviewed journal focusing on evidence-based reports on the value or lack thereof of treatments intended to prevent or delay the onset of maladaptive correlates of aging in human beings. This journal is indexed on PubMed Central, MedLine,

\section{Dovepress}

CAS, Scopus and the Elsevier Bibliographic databases. The manuscript management system is completely online and includes a very quick and fair peer-review system, which is all easy to use. Visit http://www.dovepress. com/testimonials.php to read real quotes from published authors. 